\title{
Sustitutos e injertos de piel desarrollados por ingeniería de tejidos
}

\section{Skin grafts and substitutes developed by Tissue Engineering}

\section{María Inés Chaves-Rodríguez ${ }^{1}$, Laura A. Calvo-Castro², Ricardo Alva- rado-Meza ${ }^{3}$, Olman Madrigal-Monge ${ }^{4}$, Andrea Ulloa-Fernández ${ }^{5}$, Caro- lina Centeno-Cerdas ${ }^{6}$}

Chaves-Rodríguez, M. I.; Calvo-Castro, L. A.; AlvaradoMeza, R; Madrigal-Monge, O; Ulloa-Fernández, A; Centeno-Cerdas, C. Sustitutos e injertos de piel desarrollados por ingeniería de tejidos. Tecnología en Marcha. Edición especial Ingeniería de Tejidos. Pág 46-57.

1 Ingeniera en Biotecnología. Profesora de la Escuela de Biología e Investigadora del Centro de Investigación en Biotecnología del Instituto Tecnológico de Costa Rica. Costa Rica. Teléfono: (506) 2550-9027. Correo electrónico: marchaves@itcr.ac.cr.

2 Ingeniera en Biotecnología. Máster en Microbiología. Profesora de la Escuela de Biología e Investigadora del Centro de Investigación en Biotecnología del Instituto Tecnológico de Costa Rica. Costa Rica. Teléfono: (506) 2550-9027. Correo electrónico: ancalvo@itcr.ac.cr.

3 Ingeniero en Biotecnología. Investigador del Laboratorio Nacional de Nanotecnología. Costa Rica. Correo electrónico: ricardoalvarado13@gmail.com.

4 Ingeniero en Biotecnología.Licenciado en Biotecnología. Escuela de Biología. Instituto Tecnológico de Costa Rica. Correo electrónico: madrigal.olman@gmail.com.

5 Ingeniera en Biotecnología. Investigadora del Centro de Investigación en Biotecnología del Instituto Tecnológico de Costa Rica. Correo electrónico: andreguf@gmail.com.

6 Ingeniera en Biotecnología y Máster en Ciencias Biomédicas. Profesora de la Escuela de Biología e Investigadora del Centro de Investigación en Biotecnología del Instituto Tecnológico de Costa Rica. Costa Rica. Teléfono: (506) 2550-9027. Correo electrónico: ccenteno@itcr.ac.cr. 


\title{
Palabras clave
}

Piel; cultivo celular; ingeniería de tejidos; trasplante; injerto; equivalentes epiteliales.

\section{Resumen}

La reconstrucción de tejidos y órganos mediante ingeniería de tejidos ha permitido la elaboración y comercialización de diversos sustitutos o equivalentes epiteliales, que han sido utilizados desde hace más de 30 años a escala internacional para el tratamiento de lesiones en pacientes humanos. Estos injertos o implantes se confeccionan con materiales biodegradables (naturales o polímeros sintéticos) que sirven como matrices para la adhesión y proliferación celular y pueden contener células de diversos orígenes (autólogas, alogénicas o xenogénicas). Su principal ventaja clínica consiste en proporcionar una reepitelización efectiva en lesiones de gran extensión, lo que es particularmente relevante cuando hay poco tejido disponible para hacer autoinjertos. Además, ofrecen una cobertura al lecho de la lesión, evitando la deshidratación y las infecciones microbianas. Sin embargo, aún existen numerosos retos para asegurar la funcionalidad inmediata y la permanencia a largo plazo de los implantes, así como la reproducción exacta de la estructura y fisiología normal del tejido. En Costa Rica, el Centro de Investigación en Biotecnología del Instituto Tecnológico de Costa Rica cuenta con el único laboratorio en el país dedicado al cultivo in vitro de células de piel para la reconstrucción de equivalentes epiteliales con fines terapéuticos.

\section{Keywords}

Skin; cell culture; Tissue Engineering; transplant; graft; epithelial equivalents.

\begin{abstract}
Tissue Engineering strategies for tissue and organ regeneration have allowed the fabrication and commercialization of diverse skin substitutes, which have been applied in different parts of the world on human patients over the course of the last 30 years. These grafts have been developed using biodegradable materials (of natural or synthetic origin) as scaffolds for the adhesion and proliferation of cells that may be of different origins (autologous, allogenic and xenogenic). The main clinical advantage of these materials is to provide an effective re-epitelization of large wounds, which is particularly relevant when there is little tissue available for autografts. Also, skin equivalents provide coverage for skin lesions, avoiding dehydration and microbial infections. Despite these advantages, there are still many challenges to solve including the immediate functionality and long term permanency of the grafts and the exact reproduction of the normal tissue structure and physiology. In Costa Rica, the only laboratory dedicated to in vitro skin cell culture for reconstructing epithelial equivalents with therapeutic applications is located at the Biotechnology Research Center at the Costa Rica Institute of Technology.
\end{abstract}




\section{Introducción}

La ingeniería de tejidos se basa en la obtención de nuevas estructuras tisulares tridimensionales a partir de fragmentos pequeños de tejido sano. Estas estructuras reconstruidas pueden ser trasplantadas, usualmente empleando sistemas poliméricos naturales o artificiales para el soporte de las células, con el fin de restaurar la funcionalidad parcial o total de los tejidos u órganos dañados (San Román, Gallardo, Vázquez y López, 2000; Horch, 2009; Kwan, Slater, Chang, Longaker y Gurtner, 2009). Estos dos pilares fundamentales de la ingeniería de tejidos (las células y el andamio o soporte) se complementan con la adición de factores solubles, o moléculas de señalización, de origen local y sistémico, para lograr un ambiente físico-químico apropiado que permita la reconstrucción del tejido u órgano (Estrada, Paz y López, 2006). Además, la materia prima para los injertos puede ser de origen autólogo (del mismo individuo) o alogénico (proveniente de un donador) (Böttcher-Haberzeth, Biedermann y Reichmann, 2010 y Boyce y Warden, 2002).

Si bien se han hecho grandes avances en la producción de este tipo de sustitutos, aún existen algunos problemas relacionados con el desarrollo de estructuras que ofrezcan una funcionalidad inmediata y óptima después del trasplante. En este sentido, los retos actuales incluyen la elaboración de tejidos de larga duración y adecuada vascularización (BöttcherHaberzeth et al., 2010).

Las siguientes páginas resumen el estado actual de la tecnología en el desarrollo de equivalentes dermoepidermales para el tratamiento de lesiones o afecciones de la piel (Fig. 1). Esta área de estudio de la ingeniería de tejidos ha cobrado gran importancia tanto dentro como fuera de nuestro país, y en ella se han centrado los esfuerzos multidisciplinarios del Laboratorio de Ingeniería de Tejidos del Centro de Investigación en Biotecnología (CIB) del Instituto Tecnológico de Costa Rica (ITCR).

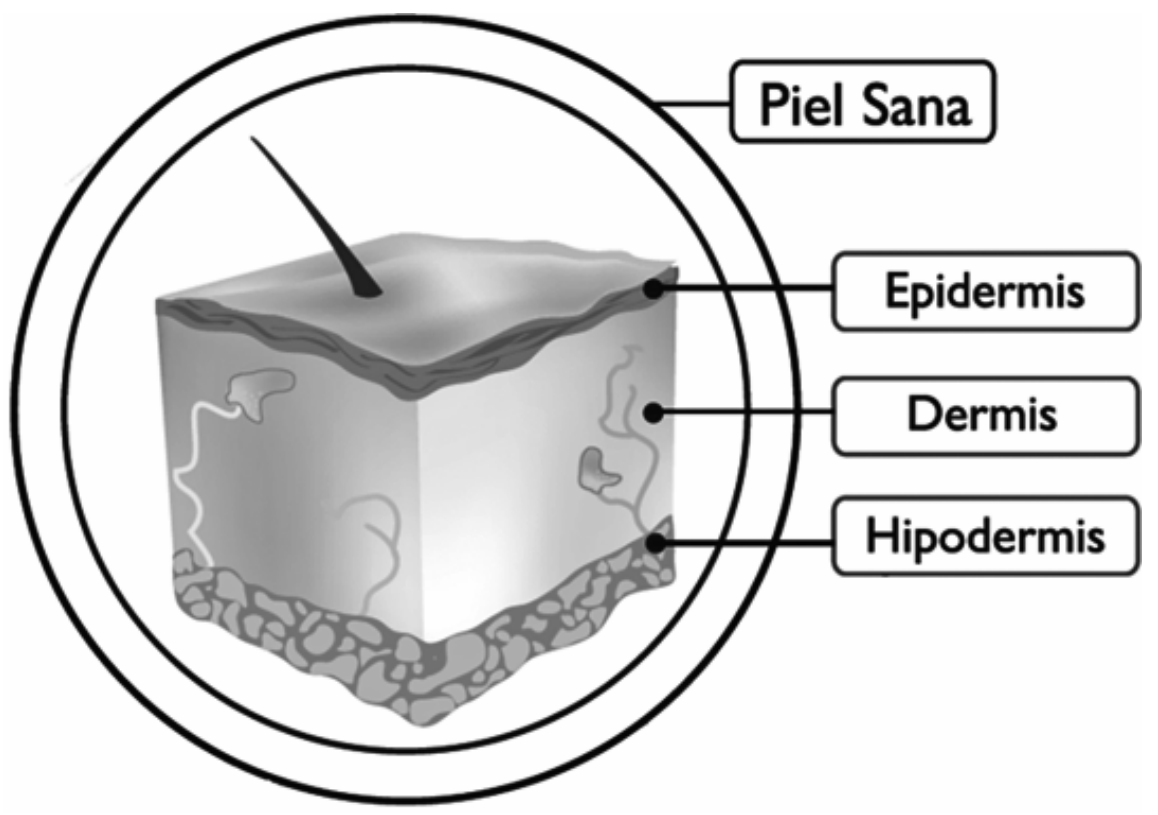

Figura 1. Estructura general de la piel humana. Como se observa en la ilustración, la piel está conformada por tres estratos: Ia epidermis, compuesta principalmente por células Ilamadas queratinocitos; la dermis, que es tejido conjuntivo de soporte compuesto principalmente de fibroblastos embebidos en matriz extracelular; y la subdermis o hipodermis, constituida principalmente por tejido graso. 


\section{Sustitutos e injertos de piel desarrollados por ingeniería de tejidos}

De acuerdo con Brychta, Adler, Rihovd y Komdrkovd (1994), el desarrollo de sustitutos o injertos mediante ingeniería de tejidos para el tratamiento de daños en la piel dio sus primeros pasos en 1950, cuando se logró la separación enzimática de la epidermis y la dermis utilizando tripsina, pero sin destruir la viabilidad de las células epiteliales. A inicios de 1960 se demostró que los queratinocitos pueden sobrevivir en cultivo artificial, mientras que en 1975 Rheinwald y Green publicaron el trabajo de referencia sobre el crecimiento y proliferación de células cutáneas in vitro, a partir del cual lograron desarrollar un epitelio trasplantable.

El trabajo de Rheinwald y Green (1975) permitió no solo establecer el cultivo in vitro de queratinocitos, sino que para 1978 se logró su cultivo en forma de pequeñas láminas para implante, y para la década de 1980 se inició la aplicación clínica de cultivos autólogos y se desarrollaron alternativas dermales sintéticas (Chern, Baum y Arpey, 2009). Sin embargo, no fue hasta la década de 1990 cuando se comprendió la codependencia entre queratinocitos y fibroblastos y, poco después, se determinó que los queratinocitos no son capaces de sobrevivir a largo plazo en caso de provenir de un donador alogénico. Sin embargo, desde 1995 se ha reportado la reconstrucción de amplias regiones de piel dañada utilizando cultivos autólogos de células epidérmicas en colágeno bovino y otras matrices de soporte análogas a las estructuras reales in vivo (MacNeil, 2007).

Se han realizado muchos esfuerzos para desarrollar sustitutos de piel sin necesidad de donantes, los cuales permitan aumentar la disponibilidad de piel para injertar en caso de lesiones masivas. En este aspecto, se debe tener en cuenta que se considera que cualquier lesión cutánea de más de $4 \mathrm{~cm}$ de diámetro no sanará correctamente sin un implante. Aunque hasta ahora no se ha podido reconstruir en su totalidad la compleja estructura de la piel, se han desarrollado diversos tipos de equivalentes monocapa o multicapa (cuadro 1), donde la monocapa más simple es equivalente a una lámina o a una suspensión de queratinocitos autólogos (Hierner et al., 2005).

Como características ideales para estos sustitutos se busca que sean capaces de resistir infecciones y soportar la hipoxia en la lesión, así como que sean resistentes, costoeficientes, fáciles de preparar, almacenar, usar y adquirir, con espesor flexible, ausencia de inmunogenicidad, resistencia a microorganismos y estabilidad a largo plazo. Además, es deseable que provean de cobertura permanente a la herida, recreando los componentes dérmicos y epidérmicos naturales (Chern et al., 2009 y Shores, Gabriel y Gupta, 2007).

Cuadro 1. Tipos de implantes para el tratamiento de lesiones en la piel.

\begin{tabular}{|c|c|}
\hline Tipo de implante & \multicolumn{1}{c|}{ Descripción } \\
\hline Tejidos naturales & $\begin{array}{l}\text { Injertos de piel propia (autoinjertos), de un donante (aloinjertos) o de origen } \\
\text { animal (xenoinjertos). También se utiliza membrana amniótica. }\end{array}$ \\
\hline \multirow{3}{*}{ Sustitutos artificiales de la piel } & $\begin{array}{l}\text { Láminas y matrices poliméricas, de estructura usualmente porosa y de origen } \\
\text { artificial, que pueden usarse como recubrimiento temporal análogo de la } \\
\text { epidermis y la dermis. }\end{array}$ \\
\hline Matrices dérmicas acelulares & $\begin{array}{l}\text { Tejido epitelial, usualmente de origen animal, tratado química o físicamente } \\
\text { para eliminar todas las células dérmicas y epidérmicas, dejando solo la } \\
\text { matriz extracelular biológicamente activa. }\end{array}$ \\
\hline Tejidos cultivados & $\begin{array}{l}\text { Fibroblastos humanos embebidos en una matriz de soporte, con o sin una } \\
\text { capa superficial análoga a la epidermis que contiene únicamente queratino- } \\
\text { citos. Pueden ser producidos de forma autóloga o alogénica. }\end{array}$ \\
\hline
\end{tabular}


Durante los últimos 30 años se han desarrollado y comercializado varios productos del tipo implante como sustitutos temporales o permanentes de la piel (Cuadro 2). Funcionalmente, su principal alcance ha sido proporcionar una cobertura al lecho de la lesión, evitando la deshidratación y las infecciones. Estos productos contienen células de diversos orígenes (autólogo, alogénico o xenogénico) y materiales biodegradables (naturales o polímeros sintéticos) que sirven como matrices para la adhesión y proliferación celular, al mismo tiempo que facilitan la manipulación para la aplicación terapéutica (Böttcher-Haberzeth et al., 2010).

Cuadro 2. Algunos productos comerciales desarrollados mediante la ingeniería de tejidos para el tratamiento de lesiones en la piel.

\begin{tabular}{|c|c|c|c|}
\hline Clasificación & Producto comercial & Estructura & Composición \\
\hline \multirow{7}{*}{$\begin{array}{l}\text { Sustitutos de la } \\
\text { epidermis }\end{array}$} & $\begin{array}{l}\text { Epicel }{ }^{\mathrm{TM}} \text { (Genzyme } \\
\text { Corporation) }\end{array}$ & & $\begin{array}{c}\text { Queratinocitos autólogos } \\
\text { cultivados. }\end{array}$ \\
\hline & $\begin{array}{l}\text { EpiDex® (Euroderm- } \\
\text { Biotech AG) }\end{array}$ & & $\begin{array}{c}\text { Autoinjerto epidérmico } \\
\text { cultivado (células del folículo). }\end{array}$ \\
\hline & $\begin{array}{c}\text { LaserSkin }^{\mathrm{TM}} \text { (Fidia } \\
\text { Advanced Biopolymers) }\end{array}$ & & $\begin{array}{c}\text { Queratinocitos autólogos } \\
\text { sobre matriz de ácido } \\
\text { hialurónico. }\end{array}$ \\
\hline & Myskin (Celltran Ltd.) & & $\begin{array}{l}\text { Queratinocitos autólogos } \\
\text { cultivados sobre una capa de } \\
\text { silicón con plasma. }\end{array}$ \\
\hline & $\begin{array}{l}\text { ReCell (Clinical Cell } \\
\quad \text { Culture C3 Ltd.) }\end{array}$ & $\begin{array}{l}0000900 \\
8000000\end{array}$ & $\begin{array}{c}\text { Suspensión celular autóloga } \\
\text { de queratinocitos. }\end{array}$ \\
\hline & $\begin{array}{l}\text { Suprathel® (Institute } \\
\text { of Textile and Process } \\
\text { Engineering) }\end{array}$ & & $\begin{array}{l}\text { Capa delgada a base de } \\
\text { ácido poliláctico. }\end{array}$ \\
\hline & $\begin{array}{c}\text { Vivoderm }{ }^{\top M} \text { (ER Squibb \& } \\
\text { Sons Inc.) }\end{array}$ & & $\begin{array}{c}\text { Queratinocitos autólogos } \\
\text { sobre matriz de ácido } \\
\text { hialurónico. }\end{array}$ \\
\hline \multirow{4}{*}{$\begin{array}{l}\text { Sustitutos de la } \\
\text { dermis }\end{array}$} & $\begin{array}{l}\text { Aloinjerto cadavérico } \\
\text { (Bancos de tejidos) }\end{array}$ & & $\begin{array}{c}\text { Piel alogénica criopreservada, } \\
\text { glicerolada, liofilizada y/o } \\
\text { irradiada. }\end{array}$ \\
\hline & Alloderm® (LifeCell) & & Aloinjerto de dermis acelular. \\
\hline & $\begin{array}{l}\text { Biobrane }^{\mathrm{TM}} \text { (Bertek } \\
\text { Pharmaceuticals Inc.) }\end{array}$ & & $\begin{array}{c}\text { Capa delgada de silicón y } \\
\text { malla de nylon sobre una capa } \\
\text { de colágeno. }\end{array}$ \\
\hline & $\begin{array}{c}\text { Dermagraft } \Theta(\text { Advanced } \\
\text { Biohealing Inc.) }\end{array}$ & & $\begin{array}{l}\text { Fibroblastos neonatales } \\
\text { inoculados en una matriz } \\
\text { bioabsorbible. }\end{array}$ \\
\hline
\end{tabular}




\begin{tabular}{|c|c|c|c|}
\hline Clasificación & Producto comercial & Estructura & Composición \\
\hline \multirow{6}{*}{$\begin{array}{l}\text { Sustitutos de la } \\
\text { dermis }\end{array}$} & $\begin{array}{l}\text { ICX-SKN (Intercytex, } \\
\text { Ltd.) }\end{array}$ & & $\begin{array}{l}\text { Fibroblastos alogénicos en su } \\
\text { propia matriz extracelular. }\end{array}$ \\
\hline & $\begin{array}{l}\text { Integra } \circledast \text { (Integra Life } \\
\text { Sciences Corporation) }\end{array}$ & & $\begin{array}{c}\text { Capa delgada de silicón sobre } \\
\text { una capa de colágeno tipo I } \\
\text { bovino y glicosaminoglicano } \\
\text { de tiburón. }\end{array}$ \\
\hline & $\begin{array}{c}\text { Matriderm } \AA(D r . \\
\text { Suwalackk Skin \& Health } \\
\text { Care AG) }\end{array}$ & & $\begin{array}{l}\text { Colágeno dermal bovino tipo I, } \\
\text { III y } \vee \text { y elastina. }\end{array}$ \\
\hline & OASIS (Healthpoint) & & $\begin{array}{c}\text { Matriz natural intacta derivada } \\
\text { de la submucosa del intestino } \\
\text { delgado porcino. }\end{array}$ \\
\hline & $\begin{array}{c}\text { Permacol }{ }^{\mathrm{TM}}(\text { Tissue } \\
\text { Science } \\
\text { Laboratories) }\end{array}$ & & $\begin{array}{l}\text { Xenoinjerto de colágeno de } \\
\text { dermis porcina acelular. }\end{array}$ \\
\hline & $\begin{array}{c}\text { TransCyte } \AA \text { (Advanced } \\
\text { Biohealing Inc) }\end{array}$ & $\therefore$ & $\begin{array}{l}\text { Fibroblastos neonatales } \\
\text { humanos cultivados en } \\
\text { colágeno y cubiertos por una } \\
\text { capa de silicón y malla de } \\
\text { nylon. }\end{array}$ \\
\hline \multirow{3}{*}{$\begin{array}{c}\text { Sustitutos } \\
\text { dermoepidérmicos }\end{array}$} & $\begin{array}{c}\text { Apligraf } ® \\
\text { (Organogenesis Inc. y } \\
\text { Novartis Corp.) }\end{array}$ & & $\begin{array}{l}\text { Queratinocitos neonatales } \\
\text { humanos sobre una capa de } \\
\text { colágeno bovino tipo I con } \\
\text { fibroblastos neonatales. }\end{array}$ \\
\hline & $\begin{array}{c}\text { OrCel } \circledast(\text { Ortec } \\
\text { International, Inc., } \\
\text { Forticell Bioscience Inc.) }\end{array}$ & & $\begin{array}{c}\text { Esponja de colágeno } \\
\text { bovino tipo I embebida } \\
\text { con fibroblastos humanos } \\
\text { neonatales con una cubierta } \\
\text { de queratinocitos humanos } \\
\text { neonatales o autólogos } \\
\text { cubiertos de gel. }\end{array}$ \\
\hline & $\begin{array}{l}\text { Autoinjertos cultivados } \\
\text { in vitro }\end{array}$ & 0 & $\begin{array}{l}\text { Fibroblastos y queratinocitos } \\
\text { autólogos cultivados in vitro. }\end{array}$ \\
\hline
\end{tabular}

Compilado de Böttcher-Haberzeth et al., 2010; Boyce y Warden, 2002; Jones, Lachlan y Robin, 2002; Flasza et al., 2007; Shores, Gabriel y Gupta, 2007 y MacNeil, 2007. Las estructuras son interpretaciones ilustrativas de los autores basadas en la descripción de la composición de los productos. La clasificación en el grupo "Sustitutos dermoepidérmicos" se refiere a materiales que contienen tanto queratinocitos como fibroblastos, aunque otros de los productos en esta lista también podrían cumplir la función dermoepidérmica.

\section{Origen del tejido y/o de las células para los sustitutos de piel}

\section{Autoimplantes (autoinjertos)}

El donador del material que compone el injerto es el mismo receptor, lo cual implica que no hay riesgo de rechazo del implante, ya que no existen problemas de compatibilidad (Wysocki y Dorsett-Martin, 2008). La principal desventaja que presentan los autoinjertos es que, 
irremediablemente, se debe generar una lesión en el sitio donador, lo que involucra dolor, cicatrización y riesgo de infección adicional a la de la lesión original. Además, en caso de pérdida de grandes áreas de piel como, por ejemplo, en los grandes quemados, no existen zonas donadoras suficientes para implantar las regiones dañadas (Loss, Wedler, Kunzi, MeuliSimmen y Meyer, 2000).

Los autoinjertos pueden ser de piel natural o de piel cultivada in vitro. Los autoinjertos cultivados in vitro tampoco presentan riesgo de rechazo pero son frágiles y deben ser manejados con cuidado y experticia, ya que las lesiones son susceptibles a reaperturas y contracciones de las cicatrices (Barret, Wolf, Desai y Herndon, 2000). La fragilidad durante los primeros días de trasplante se asocia principalmente al epitelio no cornificado y a la unión dermoepidérmica (lámina basal) incipiente, factores que hacen que esta alternativa sea más susceptible a la infección bacteriana y daño mecánico que los injertos mallados de piel natural (Reinhart et al., 2007).

Sin embargo, los autoinjertos cultivados in vitro han sido utilizados clínicamente desde 1981 como cobertura permanente, y permiten cubrir lesiones de una gran área superficial a partir de una pequeña biopsia obtenida del mismo paciente, aunque la producción de suficiente material para injertar puede tomar de 3 a 4 semanas (Loss et al., 2000 y Barret et al., 2000). Las experiencias con estos injertos son diversas, pero mayoritariamente se reportan resultados cosméticos superiores y disminución en las tasas de mortalidad. Las principales limitaciones incluyen estadías hospitalarias más prolongadas y costos hospitalarios elevados, así como la desincronización entre los requerimientos del paciente y el tiempo que toma cultivar el autoinjerto, lo que ha restringido su uso generalizado (Barret et al., 2000 y Hernon et al., 2006).

\section{Aloimplantes (aloinjertos)}

Se trata de injertos en los que el donador y el receptor son individuos diferentes pero de la misma especie, de manera que su principal ventaja consiste en su mayor disponibilidad. Los aloinjertos pueden ser obtenidos a partir de donantes vivos o fallecidos. La piel cadavérica, por ejemplo, se obtiene a partir de bancos de piel sin fines de lucro (Jones, Lachlan y Robin, 2002). Al igual que los xenoinjertos, los aloinjertos estimulan la formación de tejido de granulación, lo que facilita implantes posteriores; sin embargo, debido a que la piel es altamente inmunogénica, los aloimplantes son rechazados en aproximadamente 10 días, por lo que su carácter temporal constituye su principal limitación. En pacientes con quemaduras extensas, este período de rechazo suele prolongarse (Wysocki y Dorsett-Martin, 2008). Al igual que los autoinjertos, los aloimplantes pueden ser de piel natural o piel cultivada in vitro.

Los aloinjertos cultivados in vitro pueden obtenerse y prepararse previamente a partir de donantes vivos o piel cadavérica; además, pueden utilizarse en fresco, criopreservados o liofilizados. La liofilización permite almacenarlos convenientemente a temperatura ambiente; además, gracias a la criopreservación, se han establecido bancos de aloinjertos que presentan una funcionalidad comparable a la de los aloinjertos frescos (Kamolz, Lumenta, Kitzinger y Frey, 2008 y Chern et al., 2009). Todos los aloinjertos requieren un estricto control, mediante análisis serológicos y microbiológicos, para evaluar la presencia de enfermedades infecciosas en el material (Chern et al., 2009); cualquier tejido contaminado debe ser descartado. Al igual que los autoinjertos cultivados in vitro, los aloinjertos cultivados se limitan al tratamiento de lesiones de profundidad parcial (Wysocki y Dorsett-Martin, 2008), aunque en nuestra experiencia se han obtenido resultados exitosos en lesiones de gran profundidad, incluso con músculo y hueso expuestos.

Por otro lado, aunque se ha demostrado que existe tolerancia inmunológica a largo plazo a los fibroblastos alogénicos, para la incorporación adecuada y permanente del injerto al tejido 
basal de la lesión es esencial el uso de queratinocitos autólogos. Además, estudios recientes han señalado que el uso de fibroblastos autólogos resulta en mejoras funcionales y estéticas (Atiyeh y Costagliola, 2007).

Cabe mencionar que cuando se hace referencia a los implantes o injertos de piel natural (de donante vivo o cadavérico), existen diferencias estructurales, funcionales y aplicadas respecto a si se trata de tejido de espesor total o parcial. Los injertos de espesor parcial, que incluyen la epidermis completa y parte de la dermis, se recomiendan para lesiones de textura irregular, y suelen presentar mayor éxito en la toma del injerto, aunque pueden contraerse; pueden ser mallados para cubrir mayor superficie y permitir el intercambio de exudados y el flujo de sangre a través de la lesión. No obstante, esta alternativa produce resultados estéticos inferiores, ya que puede producir hipopigmentación o hiperpigmentación (Wysocki y Dorsett-Martin, 2008), así como cicatrización hipertrófica o queloide, la cual puede causar severas discapacidades y desfiguraciones (Böttcher-Haberzeth et al., 2010).

Por su parte, los injertos de espesor completo, que incluyen la dermis y la epidermis completas, se utilizan en lesiones pequeñas y profundas (usualmente en zonas anatómicas como articulaciones y palmas de las manos y pies), confieren mayor elasticidad, mejor protección, mejores resultados cosméticos, son más resistentes, presentan mejor compatibilidad (Wysocki \& Dorsett-Martin, 2008) y usualmente no causan cicatrización anómala (Böttcher-Haberzeth et al., 2010).

\section{Xenoimplantes (xenoinjertos)}

Estos son injertos en los que el donador es de una especie distinta a la del receptor (por ejemplo, implantes de piel de cerdo en humanos). Su principal limitante es el alto riesgo de rechazo. Aunque la utilización de tejido natural y fresco de este tipo no es común en los países occidentales, sí lo es en Oriente debido a creencias culturales que limitan el uso de aloimplantes (Wysocki y Dorsett-Martin, 2008). Sin embargo, existen diversos productos comerciales europeos y norteamericanos (Cuadro 2) que se utilizan como sustitutos de la piel que incluyen tejidos (normalmente acelulares) o proteínas de origen animal entre sus componentes.

\section{Tipos de sustitutos de piel según el tejido que reemplazan}

\section{Sustitutos de la epidermis}

Estos se refieren principalmente a queratinocitos autólogos, que a menudo se cultivan en presencia de una capa de células alimentadoras (feeder layer). La mayoría de estos sustitutos pertenece a la categoría de autoinjerto epidérmico cultivado, para lo cual los queratinocitos se cultivan en láminas de células estratificadas partiendo de una biopsia de piel del mismo paciente receptor y utilizando diferentes tipos de soportes. Otro enfoque para el reemplazo celular epidérmico es el uso de cultivos de queratinocitos autólogos en suspensión, que se pueden rociar sobre el lecho de la herida inmediatamente después de haber sido preparados a partir de una biopsia en la sala de operación. Aunque este método ha demostrado una epitelización algo más rápida en la maduración epidérmica en modelos de herida, la calidad y el beneficio para el paciente en la práctica clínica son todavía objeto de debate (BöttcherHaberzeth et al., 2010).

Sustitutos de la dermis

Se trata de preparaciones con diversa estructura, composición y costo. Algunos presentan disponibilidad inmediata y pueden ser procesados para ser inmunológicamente inertes, con una vida útil prolongada y fácil manipulación. Sin embargo, requieren de al menos un 
tratamiento subsecuente que cubra el tejido con células epidérmicas (Wysocki y Dorsett-Martin, 2008 y Chern et al., 2009). Se debe considerar que la calidad de adhesión y cicatrización de los sustitutos epidérmicos depende de las condiciones fisiológicas de la dermis sobre la que se aplican, de manera que los sustitutos dérmicos buscan restaurar el tejido dañado, promoviendo el crecimiento de nuevo tejido y la optimización de las condiciones de curación. Así, el objetivo primordial de los sustitutos de la dermis no es reepitelizar, sino aportar la secreción de factores de crecimiento y citoquinas y el depósito de proteínas típicas de la matriz dérmica (BöttcherHaberzeth et al., 2010).

\section{Sustitutos dermoepidérmicos}

Este tipo de injertos presenta una estructura análoga a la de las capas de la piel natural. En términos de resistencia mecánica y aspecto de la cicatriz, los resultados de la aplicación de estos injertos parecen ser superiores a las técnicas convencionales (Böttcher-Haberzeth et al., 2010). Además, se han reportado disminuciones en el tiempo de cicatrización y la hiperpigmentación e hipopigmentación, así como mejorías en la flexibilidad y la calidad de la cicatrización, sin reacciones inmunológicas adversas por parte del paciente receptor. Inicialmente, estos sustitutos fueron desarrollados como vendajes; recientemente se han diseñado para estimular la reepitelización y la formación de piel nueva, gracias a la secreción de factores de crecimiento (Nie et al., 2007). Los productos comerciales de este tipo (Apligraf $\circledast$ y OrCel囚) no han reportado evidencia de rechazo inmunológico. No obstante, su costo es elevado, su vida útil no es tan prolongada y su manipulación debe ser cuidadosa (Chern et al., 2009). Además, dado que los productos comerciales desarrollados utilizan piel de donantes, esto ha suscitado un debate ético sobre el uso de piel cadavérica con fines comerciales (Wysocki y Dorsett-Martin, 2008).

\section{Andamios para la reconstrucción de la piel}

La ingeniería de tejidos se basa en el uso de células y materiales de soporte sintéticos o naturales, que pueden formar una estructura de tejido en la que se mantiene la comunicación célula-célula y las interacciones célula-matriz extracelular, en la que la matriz o andamio le da soporte y funcionalidad al tejido (Jiménez y Jiménez, 2004). Los materiales de soporte utilizados para este fin deben cumplir con características como: porosidad adecuada para favorecer la integración del tejido y la vascularización, biodegradabilidad controlada, compatibilidad histoquímica (Sachlos y Czernuszka, 2003), estabilidad a largo plazo, ausencia de inmunogenicidad y citotoxicidad, así como ser accesibles (en costo y disponibilidad) y fáciles de preparar, manipular y esterilizar.

El desarrollo de un modelo de piel in vitro que sea estructural y funcionalmente similar a la piel normal ha llevado al desarrollo y estudio de numerosos andamiajes poliméricos (de origen sintético o natural) que sirvan de soporte para el cultivo de las células epiteliales (Arvelo, Perez y Cotte, 2004). Los principales polímeros sintéticos biodegradables son poliésteres, polianhidros, policaprolactona, policarbonato y polifumarato, mientras que los polímeros de origen natural incluyen proteínas naturales de las matrices extracelulares como colágeno y glicosaminoglicano, ácido algínico, quitosano y otros polipéptidos (Chen, Ushida y Tateish, 2002).

En nuestro laboratorio se ha favorecido el uso de soportes tipo gel, desarrollados a base de las proteínas del plasma sanguíneo. Este tipo de geles se suelen obtener combinando la fracción del plasma sanguíneo, rico o pobre en plaquetas, con trombina calcificada, lo cual imita la reacción fisiológica que induce la polimerización de la fibrina y provoca la formación de un material biológico suave, parecido al gel (Burnouf, Radosevich y Goubran, 2004). Un factor importante en el uso de este tipo de geles es la relativamente fácil y amplia disponibilidad de plasma sanguíneo con calidad de banco de sangre. 
Se ha observado que los geles basados en fibrina permiten un rápido crecimiento de los queratinocitos, brindando también una matriz ideal que permite un manejo fácil de la lámina de células para su trasplante, aparte de hacer posible cultivar grandes superficies sobre una base que sirve muy bien de equivalente dérmico (Arvelo et al., 2004).

\section{Ventajas y desventajas de los implantes y/o sustitutos de la piel}

La creación de sustitutos de la piel implica emular una serie de procesos que en el cuerpo humano suceden de manera autónoma, pero en el cultivo in vitro deben ser mediados de forma artificial. La ontogénesis de la piel, de ser posible, sería el método mediante el cual se lograría el desarrollo correcto de estructuras y funciones, mediado por los pasos secuenciales de citogénesis, morfogénesis, histogénesis y organogénesis. Dada la incapacidad actual de emular estos pasos, el fenotipo expresado por las células en cultivo se asemeja más al de un proceso de curación fisiológica, que incluye solo los pasos de citogénesis, morfogénesis e histogénesis, careciendo del proceso de organogénesis. Este último paso es crucial en la formación de estructuras anatómicas como las glándulas, los folículos y los nervios, y explica la inexistencia de estas estructuras en la curación postnatal (Boyce y Warden, 2002). Estos autores también mencionan una serie de limitaciones y consideraciones en el uso de sustitutos dérmicos. Entre las limitantes destacan la fragilidad mecánica, la susceptibilidad a la contaminación microbiana, bajas tasas de toma del injerto, así como un costo elevado. Por otro lado, en nuestra experiencia también ha sido relevante la necesidad de vendaje y cuidados especiales, incluyendo aplicaciones repetidas y la incapacidad de algunos pacientes de apegarse al seguimiento clínico y las recomendaciones.

En relación con los injertos cultivados in vitro, es importante considerar el tiempo que se requiere para alcanzar la confluencia necesaria para utilizar el cultivo de las células, lo cual debe estar sincronizado con los requerimientos de los pacientes. Además, se ha reportado que el autoinjerto debe ser utilizado en un periodo de 2 a 3 días, de lo contrario no se adhiere satisfactoriamente al lecho de la herida (Hernon et al., 2006). En este sentido, uno de los principales retos de la ingeniería de tejidos consiste en la disminución del tiempo requerido para alcanzar cultivos útiles, siendo que los esfuerzos se concentran en identificar queratinocitos con alta capacidad de multiplicación y fibroblastos con mayor capacidad para actuar como capas alimentadoras (Carsin et al., 2000).

Por otro lado, en los autoinjertos epiteliales cultivados obtenidos a partir de biopsias influyen factores como la asepsia de la muestra y las condiciones fisiológicas del paciente, tales como la edad y la historia clínica (si es fumador o ha sido sometido a tratamientos de quimioterapia o radioterapia); así como la secreción de exudados e infecciones en la herida. En este sentido, se ha observado que la toma del autoinjerto es más exitosa en pacientes jóvenes, debido al estado fisiológico de sus células y su mayor capacidad de respuesta para la toma del injerto (Carsin et al., 2000). Además, el éxito del tratamiento depende de la naturaleza de la herida; por ejemplo, cuando la dermis se encuentra totalmente destruida, se recomienda no utilizar sustitutos epidérmicos ya que se ha reportado que en este tipo de lesiones los injertos no presentan adherencia o funcionalidad satisfactoria dada la ausencia de células madre en la dermis residual (Böttcher-Haberzeth et al., 2010).

En términos funcionales, algunos problemas que no han sido resueltos en la elaboración de autoinjertos cultivados incluyen dudas respecto al nivel de diferenciación que debe tener el injerto al momento de ser trasplantado, de manera que pueda sostener la regeneración del tejido a largo plazo pero que exprese su función como barrera al ser aplicado; por otro lado, no se han podido elaborar injertos con una adecuada vascularización (Böttcher-Haberzeth et al., 2010). 


\section{Consideraciones finales}

En términos económicos, las alternativas terapéuticas basadas en implantes epiteliales cultivados in vitro reportan costos más elevados que los tratamientos convencionales, en parte debido a que se requiere de reactivos y medios de cultivo de alto costo, personal capacitado y equipos especializados de alta tecnología. Sin embargo, los pacientes que reciben las células autólogas cultivadas tiene tasas de mortalidad mucho menores que aquellos que reciben tratamientos convencionales. Al mismo tiempo, se reporta que en estos pacientes se ha reducido la necesidad de intervenciones quirúrgicas y el dolor causado por las lesiones (CotoSegura et al., 2007; Carsin et al., 2000 y Wood, Kolybaba y Allen, 2006). Por otro lado, cuando las lesiones no son muy extensas ni profundas, este tipo de tratamiento sí puede representar una disminución de costos, asociados principalmente a la reducción del tiempo requerido para sanar, lo que implica menos gastos en personal médico, menos insumos y menor tiempo de internamiento.

\section{Agradecimientos}

Los autores desean agradecer al Organismo Internacional de Energía Atómica y a la Vicerrectoría de Investigación y Extensión del Instituto Tecnológico de Costa Rica (ITCR), por el apoyo financiero que ha permitido el establecimiento del Laboratorio de Ingeniería de Tejidos en el CIB, ITCR. Además, agradecemos a la M.Sc. Montserrat Jarquín Cordero (Escuela de Biología, ITCR), por la revisión de este trabajo.

\section{Bibliografía}

Arvelo, F., Pérez, P. \& Cotte, C. (2004). Obtención de láminas de piel humana mediante ingeniería de tejidos. ACV, 55(1), 74-82.

Atiyeh, B. \& Costagliola, M. (2007). Cultured epithelial autograft (CEA) in burn treatment: Three decades later. Burns, 33, 405-413.

Barret, J. P., Wolf, S. E., Desai, M. H. \& Herndon, D. N. (2000). Cost-efficacy of cultured epidermal autografts in massive pediatric burns. Ann. Surg., 231(6), 869-76.

Böttcher-Haberzeth, S., Biedermann, T. \& Reichmann, E. (2010). Tissue engineering of skin. Burns, 36, 450-460.

Boyce, S. T. \& Warden, G. D. (2002). Principles and practices for treatment of cutaneous wounds with cultured skin substitutes. The American Journal of Surgery, 183, 445-456.

Brychta, R., Adler, J., Rihovd, V. \& Komdrkovd, J. (1994). Cultured skin cells for treatment of burns. Ann. Medit. Burns Club, 71(4), 206-208.

Burnouf, T., Radosevich, M. \& Goubran, H. (2004). Hemoderivados hemostáticos locales: sellador de fibrina y gel de plaquetas. Québec: Federación Mundial de Hemofilia.

Carsin, H., Ainaud, P., Le Bever, H., Rives, J., Lakhel, A., Stephanazzi, J., Lambert, F. \& Perrot, J. (2000). Cultured epithelial autografts in extensive burn coverage of severely traumatized patients: A five year single-center experience with 30 patients. Burns, 26, 379-87.

Chen, G., Ushida, T. \& Tateish, T. (2002). Scaffold design for Tissue Engineering. Macromol. Biosci., 2, 67-77.

Chern, P. L., Baum, C. L. \& Arpey, C. J. (2009). Biologic Dressings: Current applications and limitations in dermatologic surgery. Dermatol. Surg, 35(6), 891-906.

Coto-Segura, P., García, E., García, V., Fueyo-Casado, A., Vázquez-López, F., Pérez-Oliva, N. \& Meana-Infiesta, A. (2007). Efficacy of a self-made artificial skin in the treatment of chronic ulcers. Dermatol. Surg., 33(3), 392-394.

Estrada, C., Paz, C. \& López, L. (2006). Ingeniería de Tejido Óseo: Consideraciones básicas. Revista ElA, 1(5), 93-100.

Flasza, M., Kemp, P., Shering, D., Qiao, J., Marchall, D., Bokta, A. \& Johnson, P. A. (2007). Development and manufacture of an investigational human living dermal equivalent (ICX-SKN). Regen. Med. 2(6), 903-918. 
Hernon, C., Dawson, R., Freedlander, E., Short, R., Haddow, D., Brotherston, M. \& MacNeil, S. (2006). Clinical experience using cultured epithelial autografts leads to an alternative methodology for transferring skin cells from the laboratory to the patient. Regenerative Med., 1(6), 809-821.

Hierner, R., Degreef, H., Vranckx, J., Garmyn, M., Massage, P. \& van Brusse, P. (2005). Skin grafting and wound healing - the dermato-plastic team approach. Clin. Dermatol., 23(4), 343-352.

Horch, R. E. (2009). Tissue Engineering of Cultured Skin Substitutes. En: U. Meyer, T. Meyer, J. Handschel \& H. Wiesmann (Eds.), Fundamentals of Tissue Engineering and Regenerative Medicine. Alemania: Springer-Verlag.

Jiménez, P. A. \& Jiménez, S. E. (2004). Tissue and cellular approaches to wound repair. Am. J. Surg., 184(5A), 56S$64 \mathrm{~S}$.

Jones, I., Lachlan, C. \& Robin, M. (2002). A guide to biological skin substitutes. British Journal of Plastic Surgery, 55(3), 185-193. Obtenido de http://dx.doi.org/10.1054/bjps.2002.3800

Kamolz, L. P., Lumenta, D. B., Kitzinger, H. B. \& Frey, M. (2008). Tissue engineering for cutaneous wounds: an overview of current standards and possibilities. Eur. Surg., 40(1), 19-26.

Kwan, M., Slater, B., Chang, E., Longaker, M. \& Gurtner, G. (2009). Tissue Engineering Applications in Plastic Surgery. En: U. Meyer, T. Meyer, J. Handschel \& H. Wiesmann (Eds.), Fundamentals of Tissue Engineering and Regenerative. Alemania: Springer-Verlag.

Loss, M., Wedler, V., Kunzi, W., Meuli-simmen, C. \& Meyer, V. E. (2000). Artificial skin, split-thickness autograft and cultured autologous keratinocytes combined to treat a severe burn injury of 93\% of TBSA. Burns, 26, 644-652.

MacNeil, S. (2007). Progress and opportunities for tissue-engineered skin. Nature, 445, 874-880. doi:10.1038/nature05664

Nie, X., Zhang, J. Y., Cai, K. J., Yang, M. H., Xiao, A. H., Hu, H. D., Liu, L. Y., Wang, H. J., Ning, W. \& Jin, Y. (2007). Cosmetic improvement in various acute skin defects treated with tissue-engineered skin. Artificial Organs, 31(9), 703-710.

Reinhart, U., Stern-Straeter, J., Riedel, K., Bran, G., Hörmann, K. \& Riedel, F. (2007). Tissue engineering in head and neck reconstructive surgery: what type of tissue do we need? Eur. Arch. Otorhinolaryngol., 264(11), $1343-1356$.

Rheinwald, J. \& Green, H. (1975). Formation of a keratinizing epithelium in culture by a cloned cell line derived from teratoma. Cell, 6, 317-330.

Sachlos, E. \& Czernuszka, J. (2003). Making tissue engineering scaffolds work. Review on the application of solid freeform fabrication technology to the production of tissue engineering scaffolds. European Cells and Materials, 5, 29-40.

San Román, J., Gallardo, A., Vázquez, B. \& López Bravo, A. (2000). Ingeniería de tejidos: contribución de los polímeros al desarrollo de los procesos de regeneración tisular. Anales de la Real Sociedad Española de Química, 1, 5-18.

Shores, J. T., Gabriel, A. \& Gupta, S. (2007). Skin substitutes and alternatives: A Review. Adv. Skin Wound Care, 20,493-508.

Wood, F., Kolybaba, M. \& Allen, P. (2006). The use of cultured epithelial autograft in the treatment of major burn injuries: A critical review of the literature. Burns, 32, 395-401.

Wysocki, A. \& Dorsett-Martin, W. (2008). New Advances in skin substitutes, dermal fillers and other products have expanded the surgical approaches that can be considered to cover tissue defects. ORNurse, 2(9), 30-38. 